\title{
Efficacy of salmeterol/fluticasone propionate by GOLD stage of chronic obstructive pulmonary disease: analysis from the
} randomised, placebo-controlled TORCH study

\author{
Christine R Jenkins* ${ }^{* 1}$, Paul W Jones ${ }^{\dagger 2}$, Peter MA Calverley ${ }^{\dagger 3}$, \\ Bartolome Celli $^{\dagger 4}$, Julie A Anderson ${ }^{\dagger 5}$, Gary T Ferguson ${ }^{\dagger 6}$, Julie C Yates ${ }^{\dagger 7}$, \\ Lisa R Willits ${ }^{\dagger 5}$ and Jörgen Vestbo ${ }^{\dagger 8,9}$
}

Address: ' ${ }^{W}$ Woolcock Institute of Medical Research, Sydney, Australia, ${ }^{2}$ Division of Cardiac and Vascular Science, St George's, University of London, London, UK, ${ }^{3}$ University Hospital, Liverpool, UK, ${ }^{4}$ St Elizabeth's Medical Centre, Boston, USA, ${ }^{5}$ GlaxoSmithKline (GSK), Stockley Park, UK, ${ }^{6}$ Pulmonary Research Institute of Southeast Michigan, Livonia, USA, ${ }^{7}$ GSK, Research Triangle Park, USA, ${ }^{8}$ Wythenshawe Hospital, Manchester, UK and ${ }^{9}$ Hvidovre Hospital, Hvidovre, Denmark

Email: Christine R Jenkins* - crj@med.usyd.edu.au; Paul W Jones - pjones@sgul.ac.uk; Peter MA Calverley - pmacal@liv.ac.uk; Bartolome Celli - bcelli@semc.org; Julie A Anderson - julie.a.anderson@gsk.com; Gary T Ferguson - garytferguson@msn.com; Julie C Yates - julie.c.yates@gsk.com; Lisa R Willits - lisa.r.willits@gsk.com; Jörgen Vestbo - jvestbo@man.ac.uk

* Corresponding author †Equal contributors

Published: 30 June 2009

Respiratory Research 2009, 10:59 doi:10.1 186/1465-9921-10-59

This article is available from: http://respiratory-research.com/content/10/1/59

(C) 2009 Jenkins et al; licensee BioMed Central Ltd.

This is an Open Access article distributed under the terms of the Creative Commons Attribution License (http://creativecommons.org/licenses/by/2.0), which permits unrestricted use, distribution, and reproduction in any medium, provided the original work is properly cited.
Received: 29 May 2009

Accepted: 30 June 2009

\begin{abstract}
Background: The efficacy of inhaled salmeterol plus fluticasone propionate (SFC) in patients with severe or very severe COPD is well documented. However, there are only limited data about the influence of GOLD severity staging on the effectiveness of SFC, particularly in patients with milder disease.

Methods: TORCH was a 3-year, double-blind, placebo-controlled trial of 6112 patients with moderate/severe COPD with pre-bronchodilator $\mathrm{FEV}_{1}<60 \%$ predicted (mean age 65 years, $76 \%$ male, mean $44 \%$ predicted $\mathrm{FEV}_{1}, 43 \%$ current smokers). To understand the relative efficacy of SFC and its components by GOLD stages, we conducted a post-hoc analysis of the TORCH dataset using baseline post-bronchodilator $\mathrm{FEV}$, to segment patients into three groups: moderate COPD (GOLD stage II and above: $\geq 50 \% ; n=2156$ ), severe COPD (GOLD stage III: $30 \%$ to $<50 \% ; n=$ 3019 ) and very severe COPD (GOLD stage IV: $<30 \% ; n=937$ ).

Results: Compared with placebo, SFC improved post-bronchodilator $\mathrm{FEV}_{1}$ : $10 \mathrm{I} \mathrm{ml}(95 \%$ confidence interval [Cl]: 7I, I32) in GOLD stage II, $82 \mathrm{ml}(95 \% \mathrm{Cl}: 60,104)$ in GOLD stage III and $96 \mathrm{ml}(95 \% \mathrm{Cl}: 54,138)$ in GOLD stage IV patients, and reduced the rate of exacerbations: $31 \%$ (95\% Cl: 19, 40) in GOLD stage II, $26 \%(95 \% \mathrm{Cl}: 17,34)$ in GOLD stage III and $14 \%(95 \% \mathrm{Cl}:-4$, 29) in GOLD stage IV. SFC improved health status to a greater extent than other treatments regardless of baseline GOLD stage. Similarly, SFC reduced the risk of death by $33 \%$ (hazard ratio [HR] 0.67; 95\% Cl: $0.45,0.98$ ) for GOLD stage II, $5 \%$ (HR 0.95; 95\% Cl: $0.73,1.24$ ) for GOLD stage III, and $30 \%$ (HR 0.70; $95 \%$ Cl: 0.47, I.05) for GOLD stage IV. The rates of adverse events were similar across treatment arms and increased with disease severity. Overall, there was a higher incidence of pneumonia in the fluticasone propionate and SFC arms, compared with other treatments in all GOLD stages.
\end{abstract}


Conclusion: In the TORCH study, SFC reduced moderate-to-severe exacerbations and improved health status and FEV , across GOLD stages. Treatment with SFC may be associated with reduced mortality compared with placebo in patients with GOLD stage II disease. The effects were similar to those reported for the study as a whole. Thus, SFC is an effective treatment option for patients with GOLD stage II COPD.

Trial registration: Clinicaltrial.gov registration NCT002682 I6; Study number: SCO30003

\section{Background}

The last decade has seen a series of randomized controlled trials (RCTs) of pharmacological treatment which have provided a strong evidence base for the role of drug treatment in the management of chronic obstructive pulmonary disease (COPD) [1]. The efficacy of inhaled corticosteroid/long-acting $\beta$-agonist (ICS/LABA) combinations, including the salmeterol/fluticasone propionate combination (SFC), in COPD has been clearly shown for many clinically relevant outcomes including exacerbation frequency, rate of lung function decline and health status in patients with severe and very severe COPD (GOLD stages III and IV) [2-4]. To date there has been a paucity of information about the effectiveness of these agents in patients with GOLD stage II COPD, with the robustness of any clinical conclusions drawn being limited by the relatively small size of the subgroups reported [5].

Previous RCTs examining treatment effects with these drugs recruited patients entirely or predominantly from GOLD stages III and IV [6-9]. These data contributed to COPD treatment guidelines recommending the use of ICS/LABA combinations to reduce the frequency and severity of exacerbations and improving lung function and health status in patients with more severe COPD (forced expiratory volume in one second $\left[\mathrm{FEV}_{1}\right]<50 \%$ predicted) and a history of exacerbations. The absence of RCT data applicable to patients with GOLD stage II COPD can now be redressed through analysis of the results in patients with milder disease in recent large trials $[2,10]$.

The TORCH study is the largest trial of pharmacotherapy ever undertaken in COPD. It randomized over 6000 patients, and investigated the effects of SFC, salmeterol (SAL), fluticasone propionate (FP) and placebo on mortality, lung function, exacerbations and quality of life in patients with COPD. The study included patients with a pre-bronchodilator $\mathrm{FEV}_{1}$ of less than $60 \%$ predicted irrespective of their prior exacerbation history [11]. As GOLD stages of severity are defined by the post-bronchodilator $\mathrm{FEV}_{1}$, a substantial proportion of TORCH participants had GOLD stage II disease. The TORCH data therefore provide a unique opportunity to analyse the clinical efficacy and adverse events (AEs) profile of SFC and its components (SAL and FP) in patients at different stages of COPD. In this post-hoc analysis we have focussed on the effects of SFC on mortality, exacerbations, lung function and quality of life by GOLD stage, with particular emphasis on patients with diagnosed GOLD stage II disease.

\section{Methods}

Full details of the TORCH methodology have been published previously $[2,11]$.

\section{Patients}

Current or former smokers with at least a 10-pack-year history, aged between 40 and 80 years, with a confirmed

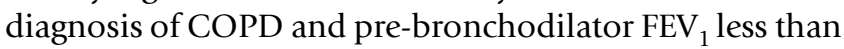
$60 \%$ of the predicted value were enrolled in the TORCH study. In addition, patients were required to show less than $10 \%$ reversibility (as a percentage of predicted $\mathrm{FEV}_{1}$ ) to $400 \mu \mathrm{g}$ salbutamol and a $\mathrm{FEV}_{1} /$ forced vital capacity (FVC) ratio of 0.70 or less. Patients were excluded if they had a diagnosis of asthma or other non-COPD respiratory disorder, any other condition likely to cause death within 3 years, previous lung volume reduction surgery and/or lung transplantation, a requirement for oxygen therapy for at least 12 hours per day, current use of oral corticosteroid therapy, or experienced an exacerbation requiring systemic oral corticosteroid therapy and/or hospitalization during the run-in period. All patients gave written informed consent. The study was approved by local ethics review committees and was conducted in accordance with the Declaration of Helsinki and Good Clinical Practice guidelines.

\section{Study design}

The TORCH study design has been described in detail in previous publications $[2,11]$. Briefly, 6112 patients at 439 centres in 42 countries were included in the efficacy analyses and 6184 patients at 444 centres were included in the safety analyses. Patients were randomized using a doubleblind parallel group design to receive twice-daily administration of SAL $50 \mu \mathrm{g}$, FP $500 \mu \mathrm{g}$, SFC $50 \mu \mathrm{g} / 500 \mu \mathrm{g}$, or placebo for 3 years. The primary efficacy outcome was allcause mortality over 3 years, regardless of whether patients withdrew from the study early. Secondary outcomes were exacerbation rate, health status, lung function and AEs while on treatment. 


\section{GOLD stage analysis}

For this post-hoc analysis, baseline post-bronchodilator $\mathrm{FEV}_{1}$ was used to group patients into GOLD-stage categories. At baseline, the highest of three acceptable measurements of $\mathrm{FEV}_{1}$ was recorded 30 minutes after inhalation of $400 \mu \mathrm{g}$ salbutamol via metered-dose inhaler and Volumatic spacer (ELLIPSE at US centres). The GOLD stages are categorized as follows: stage II corresponds to postbronchodilator $\mathrm{FEV}_{1} 50 \%$ to $<80 \%$ predicted, stage III to $30 \%$ to $<50 \%$ predicted, and stage IV to $<30 \%$ predicted [1]. In this post-hoc analysis of TORCH, the GOLD stage II category included 28 patients (five, two, nine and 12 in the placebo, SAL, FP and SFC treatment arms, respectively) with a post-bronchodilator $\mathrm{FEV}_{1} \geq 80 \%$ (GOLD stage I).

\section{Statistical analysis}

Time to all-cause mortality was analyzed using the logrank test, stratified by smoking status. Exacerbation rates were analyzed using a generalized linear model (assuming the Negative Binomial distribution, to account for patient variability), adjusted for age, gender, body mass index (BMI), baseline $\mathrm{FEV}_{1}$, previous exacerbations, region and smoking status. Quality of life was determined using the St George's Respiratory Questionnaire (SGRQ). Total SGRQ scores were analyzed as changes from baseline values using repeated measures analysis of covariance (ANCOVA), using the covariates age, gender, BMI, baseline $\mathrm{FEV}_{1}$, baseline SGRQ, region and smoking status. Post-bronchodilator $\mathrm{FEV}_{1}$ was analyzed using repeated measures ANCOVA with covariates of age, gender, BMI, baseline $\mathrm{FEV}_{1}$, region and smoking status. The rate of decline in $\mathrm{FEV}_{1}$ was analyzed using a random coefficients model adjusted for the same covariates, with random patient effects. AEs and serious AEs (SAEs) were coded using the Medical Dictionary for Regulatory Affairs (MedDRA, version 8.1) and summarized by treatment arm. Time to first pneumonia analyzed using the log-rank test, stratified by smoking status and was compared across treatment arms using Kaplan-Meier estimates. Pneumonia rates were expressed as per 1000 treatment years, by dividing the total number of events by the total time on treatment in years, then multiplying by 1000 .

To determine whether the treatment effects were consistent across severity groups, the interaction of treatment by severity group was tested for each endpoint.

\section{Results \\ Demographics}

Baseline characteristics were similar across groups when stratified by GOLD stage (Table 1). The main differences between the groups were that the GOLD stage IV group had a higher proportion of males ( $83 \%$ versus $76 \%$ and $72 \%$ in the GOLD stage III and II groups), contained more former smokers (66\% versus $57 \%$ and $53 \%$ in the GOLD stage III and II groups) and experienced more exacerbations requiring oral corticosteroids or antibiotics in the year prior to the study (mean of 1.3 versus 1.0 and 0.9 in the GOLD stage III and II groups). Baseline SGRQ total scores were higher with increasing disease severity, defined spirometrically. Mean reversibility within each GOLD stage was less than $5 \%$ of the predicted $\mathrm{FEV}_{1}$ (Table 1). A total of 16 patients violated the entry criteria and had reversibility $10-15 \%$ (six on placebo, three on SAL, six on FP and one on SFC). Of patients categorized as GOLD

Table I: Demographic and baseline characteristics by GOLD stage*

\begin{tabular}{|c|c|c|c|c|}
\hline Variable & $\begin{array}{c}\text { Stage IV } \\
\text { (<30\% predicted }) \\
(n=937)\end{array}$ & $\begin{array}{c}\text { Stage III } \\
\text { (30\% to }<50 \% \text { predicted) } \\
(n=3019)\end{array}$ & $\begin{array}{c}\text { Stage II } \\
(\geq \mathbf{5 0 \%} \text { predicted }) \\
(n=2156)\end{array}$ & $\begin{array}{l}\text { Total population } \\
\quad(n=6112)\end{array}$ \\
\hline age, mean (years) & $64.2 \pm 7.8$ & $65.4 \pm 8.1$ & $64.9 \pm 8.7$ & $65.0 \pm 8.3$ \\
\hline male $(\%)$ & 83 & 76 & 72 & 76 \\
\hline BMI, mean $\left(\mathrm{kg} / \mathrm{m}^{2}\right)$ & $23.5 \pm 4.9$ & $25.1 \pm 5.0$ & $26.6 \pm 5.2$ & $25.4 \pm 5.2$ \\
\hline $\begin{array}{l}\text { smoking status: current }(\%) \\
\text { exacerbations }\end{array}$ & 34 & 43 & 47 & 43 \\
\hline $\begin{array}{l}\text { number requiring antibiotics and/or oral } \\
\text { corticosteroids, mean }\end{array}$ & $1.3 \pm 1.5$ & $1.0 \pm 1.4$ & $0.9 \pm 1.2$ & $1.0 \pm 1.3$ \\
\hline number requiring hospitalization, mean & $0.4 \pm 0.7$ & $0.3 \pm 0.7$ & $0.2 \pm 0.5$ & $0.2 \pm 0.6$ \\
\hline post-bronchodilator $\mathrm{FEV}_{1}$, mean $(\mathrm{ml})$ & $704 \pm 160$ & $1108 \pm 263$ & $1616 \pm 399$ & $1226 \pm 443$ \\
\hline$\%$ predicted post-bronchodilator $\mathrm{FEV}_{1}$, mean & $24.6 \pm 4.0$ & $40.1 \pm 5.7$ & $58.8 \pm 7.4$ & $44.3 \pm 13.4$ \\
\hline SGRQ score, mean & $(n=730)$ & $(n=2460)$ & $(n=1761)$ & $(n=4951)$ \\
\hline total score & $56.5 \pm 15.0$ & $50.0 \pm 16.5$ & $45.4 \pm 17.7$ & $49.3 \pm 17.1$ \\
\hline symptoms score & $67.0 \pm 18.0$ & $63.5 \pm 19.3$ & $60.3 \pm 21.0$ & $62.9 \pm 19.9$ \\
\hline activity score & $73.4 \pm 16.7$ & $64.1 \pm 19.0$ & $57.1 \pm 20.6$ & $63.0 \pm 20.0$ \\
\hline impact score & $43.6 \pm 18.6$ & $37.7 \pm 18.8$ & $33.6 \pm 19.6$ & $37.1 \pm 19.3$ \\
\hline reversibility as $\%$ of predicted $\mathrm{FEV}_{1}$, mean & $2.5 \pm 3.2$ & $3.6 \pm 3.6$ & $4.3 \pm 4.0$ & $3.7 \pm 3.7$ \\
\hline
\end{tabular}

*Plus-minus values are mean \pm standard deviation 
stage II, most had post-bronchodilator $\mathrm{FEV}_{1}$ at baseline of $50 \%$ to $<60 \%$, however there were 796 patients $(37 \%)$ with $\mathrm{FEV}_{1} \geq 60 \%$ (Table 2).

\section{Withdrawal}

Increasing severity by GOLD staging was associated with a higher probability of withdrawal over the 3-year study. More patients withdrew in the placebo arm compared with the SFC arm in all severity stages, and the lowest rate of withdrawals across all treatments was in patients in GOLD stage II (Figure 1).

\section{Mortality}

In GOLD stage II, the risk of death was reduced by $33 \%$ (HR $0.67 ; 95 \%$ CI: $0.45,0.98 ; 11.4 \%$ of the patients died on placebo compared with $7.8 \%$ on SFC). The absolute risk reduction was $3.6 \%$. The risk of death was reduced by 5\% (HR 0.95; 95\% CI: 0.73, 1.24) in GOLD stage III patients and by 30\% (HR 0.70; 95\% CI: $0.47,1.05$ ) in GOLD stage IV patients (Figure 2).

The effects of SAL and FP on the probability of death versus placebo or SFC were generally similar across GOLD stages (Figure 2).

\section{Moderate/severe exacerbation rates}

SFC reduced the annual rate of exacerbations by $31 \%$ (CI: 19,40 ) compared with placebo (mean of $0.57 /$ year in SFC versus 0.82 /year in placebo) in patients with GOLD stage II COPD. Patients with GOLD stage III and IV COPD also experienced a reduction in exacerbations. Compared with placebo, SFC reduced the number of exacerbations in patients with GOLD stage III COPD by $26 \%$ (CI: 17,34$)$ per year (mean of 0.91 /year for SFC versus 1.24 /year for placebo). In patients with GOLD stage IV COPD, SFC reduced exacerbations by $14 \%$ (CI: $-4,29)$ per year versus placebo (mean of 1.54 /year for SFC versus 1.79 /year for placebo) (Figure 3).

\section{FEV ,}

Improvements in $\mathrm{FEV}_{1}$ with SFC versus placebo were 101 $\mathrm{ml}(95 \% \mathrm{CI}: 71,132)$ in GOLD stage II patients, $82 \mathrm{ml}$ (95\% CI: 60, 104) in GOLD stage III patients and $96 \mathrm{ml}$ (95\% CI: 54, 138) in GOLD stage IV patients (Figure 4).
The reduction in the rate of decline in $\mathrm{FEV}_{1}$ with SFC versus placebo was $16 \mathrm{ml} /$ year $(95 \% \mathrm{CI}: 0,32)$ in GOLD stage II patients, $16 \mathrm{ml} /$ year $(95 \% \mathrm{CI}: 5,28)$ in GOLD stage III patients and $11 \mathrm{ml} /$ year $(95 \% \mathrm{CI}:-8,30)$ in GOLD stage IV patients (Figure 5).

\section{Health status}

The greatest improvement relative to placebo was observed in those patients with more severe disease treated with SFC (Figure 6). The difference in adjusted mean change in SGRQ for SFC versus placebo was -2.3 (95\% CI: -4.0, -0.7) in GOLD stage II, -3.3 (95\% CI: -4.7, $-1.9)$ in GOLD stage III and -5.9 (95\% CI: $-8.7,-3.0)$ in GOLD stage IV. A numerical trend to greater improvement in SGRQ with worsening GOLD stage was noted with all active treatments, however this was not statistically significant.

\section{Treatment interaction}

There was no evidence of a difference in treatment effect across the GOLD stages on all-cause mortality $(\mathrm{p}=0.402$ for the interaction test), exacerbations $(p=0.254)$, postbronchodilator $\mathrm{FEV}_{1}(\mathrm{p}=0.298)$, rate of decline in $\mathrm{FEV}_{1}(\mathrm{p}$ $=0.830)$ or SGRQ $(\mathrm{p}=0.321)$.

\section{Safety}

Consistent with the results from the original analysis, the incidence of any AE was similar across the treatment arms, irrespective of GOLD stage. The incidence of SAEs and fatal AEs was also similar across treatment arms, and increased with increasing disease severity (Table 3 ). The most frequently reported AE, irrespective of GOLD stage, was an exacerbation of COPD.

The incidence of pneumonia increased with disease severity, irrespective of treatment. The probability of pneumonia as an AE was increased in patients receiving ICScontaining therapy (SFC, FP) compared with those patients not receiving ICS (SAL, placebo) in all GOLD stages (Table 4; Figure 7). When investigating treatment interactions for time to first pneumonia, there was no evidence of treatment differences across GOLD stages ( $\mathrm{p}=$ $0.402)$.

Table 2: Post-bronchodilator FEV $\%$ predicted at baseline

\begin{tabular}{|c|c|c|c|c|c|}
\hline FEV,$\%$ predicted, n (\%) & $\begin{array}{c}\text { placebo } \\
(n=1524)\end{array}$ & $\begin{array}{c}\text { SAL } \\
(n=152 \mid)\end{array}$ & $\begin{array}{c}\text { FP } \\
(n=1534)\end{array}$ & $\begin{array}{c}\text { SFC } \\
(n=1533)\end{array}$ & $\begin{array}{c}\text { total } \\
(n=6|| 2)\end{array}$ \\
\hline$<30 \%$ & $214(14)$ & $260(17)$ & $220(14)$ & $243(16)$ & 937 (15) \\
\hline $30 \%$ to $<50 \%$ & $775(5 \mathrm{I})$ & 739 (49) & $777(5 \mathrm{I})$ & $728(47)$ & 3019 (49) \\
\hline $50 \%$ to $<60 \%$ & 347 (23) & $335(22)$ & $329(21)$ & $349(23)$ & $1360(22)$ \\
\hline $60 \%$ to $<70 \%$ & $148(10)$ & $160(11)$ & $165(11)$ & $173(11)$ & $646(\mathrm{II})$ \\
\hline $70 \%$ to $<80 \%$ & $35(2)$ & $25(2)$ & $34(2)$ & $28(2)$ & $122(2)$ \\
\hline$\geq 80 \%$ & $5(<1)$ & $2(<1)$ & $9(<1)$ & $12(<1)$ & $28(<1)$ \\
\hline
\end{tabular}




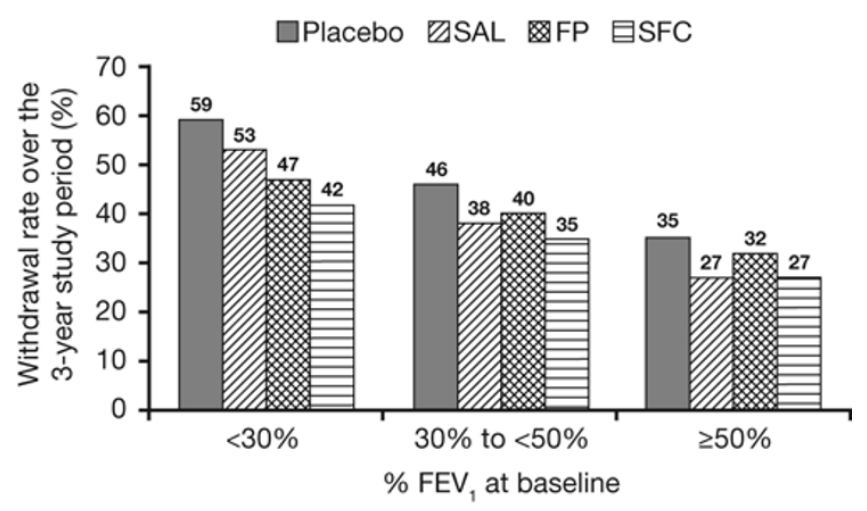

Figure I

Rate of withdrawal of patients over the 3-years duration of the study by baseline post-bronchodilator FEV, \% predicted.

\section{Discussion}

Large prospective randomized clinical trials are designed to report their pre-specified outcomes in the recruited population. However, clinicians are also interested in whether treatment responses vary within specific subsets of patients which, in the case of COPD, have been defined in terms of the post-bronchodilator $\mathrm{FEV}_{1}$ thresholds used in the GOLD guidelines. Indeed guidelines require this type of post-hoc analysis since they encourage more targeted therapy to specific patient groups. Based on the size of studies like TORCH and UPLIFT [10], there is reasonable power to conduct exploratory post-hoc analysis of secondary outcomes. In the case of TORCH, where approximately one-third of the TORCH study population fell into the GOLD stage II category, the present post-hoc
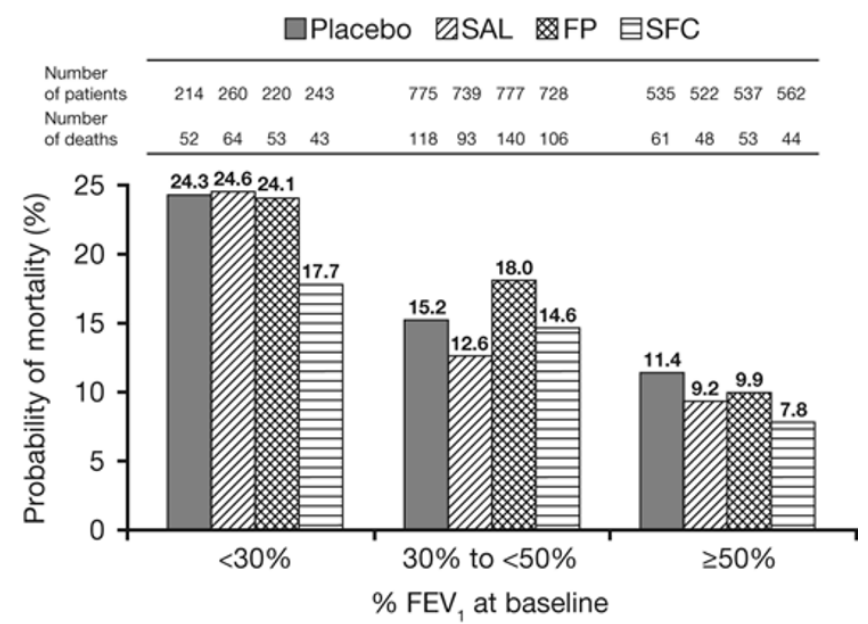

Figure 2

All-cause mortality by baseline post-bronchodilator FEV , \% predicted.

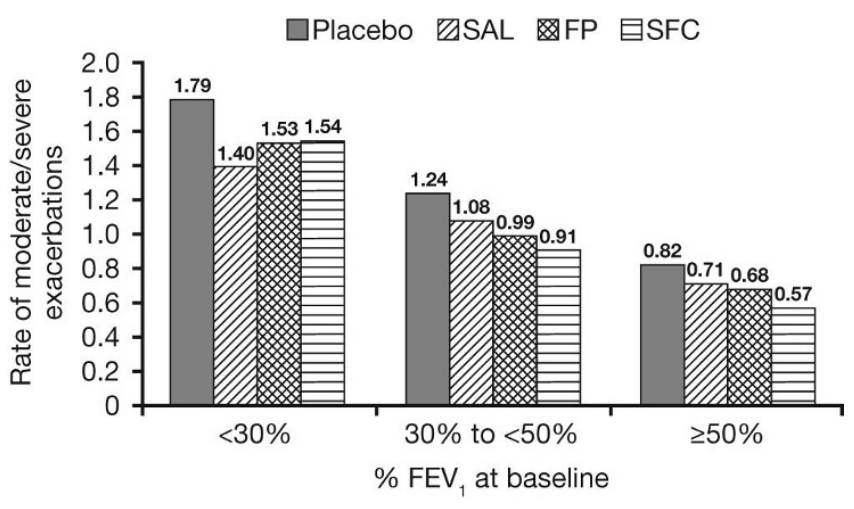

Figure 3

Exacerbation rate by baseline post-bronchodilator FEV, \% predicted.

analysis demonstrates that SFC improved SGRQ, reduced exacerbations and improved lung function when compared with placebo. SFC was also associated with reduced mortality in GOLD stage II patients, compared with placebo.

TORCH recruited patients with a history of COPD, reversibility to salbutamol of $<10 \%$ of predicted $\mathrm{FEV}_{1}$ and excluded patients with a diagnosis of asthma. Reversibility to bronchodilation has been shown to be variable within COPD patients and the presence or absence of reversibility on a single test is not an important criterion to predict response to ICS [12]. A very small number of patients in TORCH (16 patients) were protocol violators on the reversibility entry criterion.

The primary purpose of the TORCH trial was to determine whether SFC reduced all-cause mortality compared with placebo treatment (effectively regular short-acting bron-

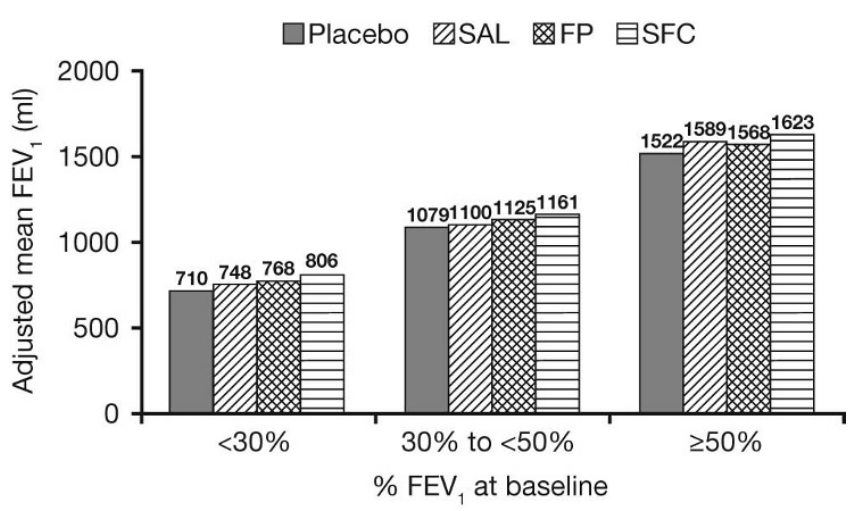

Figure 4

Adjusted mean FEV, over 3 years by baseline postbronchodilator FEV, \% predicted. 


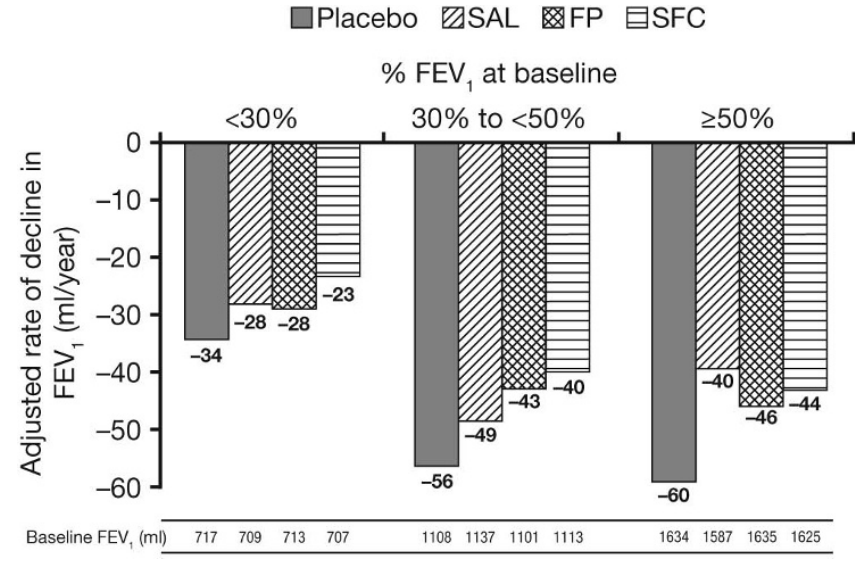

Figure 5

Rate of decline in FEV, by baseline post-bronchodilator FEV, \% predicted.

chodilator therapy). As discussed elsewhere [2], TORCH was probably underpowered to show this difference in a 4-arm study design and so particular caution is needed when interpreting mortality data between GOLD stage subgroups in this post-hoc analysis. However, while patients showed an increased risk of dying as their baseline spirometry worsened, there was a lower mortality with SFC treatment even in those with GOLD stage II disease. Clearly this finding should be confirmed by further prospective studies.

As expected, the burden of disease increased with severity regardless of the endpoint measured (mortality, exacerbations, $\mathrm{FEV}_{1}$, and AEs). All subgroup analyses should be treated with caution. However, treatment to prevent exacerbations seemed just as effective whatever the GOLD stage. The exacerbation frequency on placebo was lowest

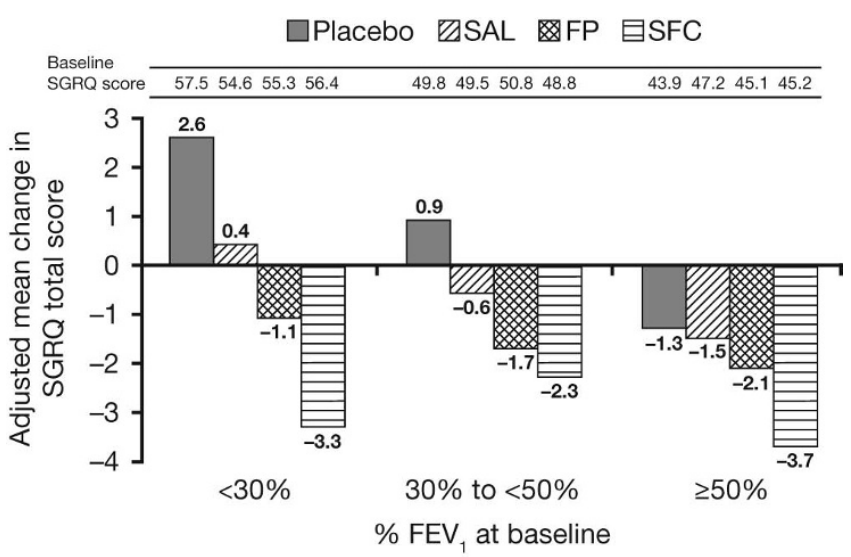

Figure 6

Improvement (reduction) in SGRQ vs placebo by baseline post-bronchodilator FEV, \% predicted.

in GOLD stage II, but was not negligible with a rate of 0.82 events per year. We observed the same proportionate reduction in events with SFC therapy in GOLD stage II patients suggesting that treatment would be worthwhile for these patients. Deterioration in health status was seen over 3 years in the placebo arm in patients with GOLD stages III and IV, but those in GOLD II showed a small improvement. SFC improved health status by approximately the same amount from baseline in all three GOLD stages. In patients with more severe disease, the main effect of SFC appears to be to slow the rate of progression relative to placebo. However, it is clear that patients in GOLD stage II do have better health status when treated with SFC compared with placebo, with a change of over two units in total score maintained over the 3 years of study.

Table 3: Incidence of adverse events by post bronchodilator $\%$ predicted $\mathrm{FEV}_{1}$ *

\begin{tabular}{|c|c|c|c|c|}
\hline Variable & $\begin{array}{c}\text { Placebo } \\
(\mathrm{n}=1544)\end{array}$ & $\begin{array}{c}\text { SAL } \\
(n=1542)\end{array}$ & $\begin{array}{c}\text { FP } \\
(n=1552)\end{array}$ & $\begin{array}{c}\text { SFC } \\
(n=1546)\end{array}$ \\
\hline \multicolumn{5}{|l|}{ FEV $_{1}<30 \%$ predicted } \\
\hline n & 215 & 261 & 223 & 246 \\
\hline any $\mathrm{AE}, \mathrm{n}(\%)$ & $198(92)$ & $24 I(92)$ & $212(95)$ & $230(93)$ \\
\hline serious AEs, n (\%) & $108(50)$ & $142(54)$ & $129(58)$ & $134(54)$ \\
\hline fatal AEs, n (\%) & $26(12)$ & $35(13)$ & $35(16)$ & $25(10)$ \\
\hline \multicolumn{5}{|c|}{ FEV, $30 \%$ to $<\mathbf{5 0} \%$ predicted } \\
\hline n & 786 & 750 & 785 & 735 \\
\hline any $\mathrm{AE}, \mathrm{n}(\%)$ & $717(91)$ & $669(89)$ & $702(89)$ & $664(90)$ \\
\hline serious $A E s, n(\%)$ & $322(4 I)$ & $306(4 I)$ & $357(45)$ & $327(44)$ \\
\hline fatal AEs, n (\%) & $70(9)$ & $62(8)$ & $87(11)$ & $62(8)$ \\
\hline \multicolumn{5}{|l|}{ FEV $_{1} \geq \mathbf{5 0} \%$ predicted } \\
\hline n & 543 & 531 & 544 & 565 \\
\hline any $A E, n(\%)$ & $470(87)$ & 47I (89) & $481(88)$ & $487(86)$ \\
\hline serious AEs, n (\%) & $197(36)$ & $174(33)$ & $169(31)$ & $198(35)$ \\
\hline fatal AEs, $n(\%)$ & $37(7)$ & $29(5)$ & $38(7)$ & $27(5)$ \\
\hline
\end{tabular}

*Safety population $(n=6184)$ 


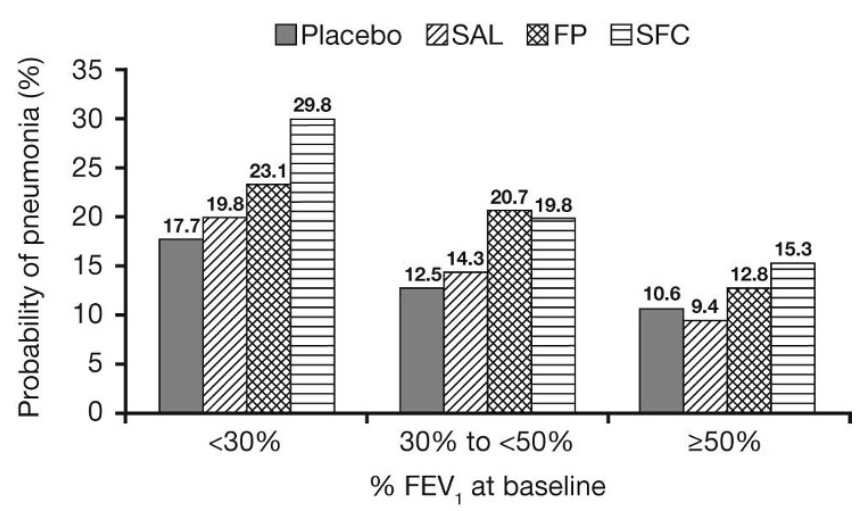

Figure 7

Probability* of pneumonia by 156 weeks by baseline post-bronchodilator FEV $_{1} \%$ predicted. *Kaplan-Meier probability.

The treatment effects on post-bronchodilator $\mathrm{FEV}_{1}$ followed a similar pattern across all GOLD stages. The rate of decline in $\mathrm{FEV}_{1}$ tended to be slightly lower in GOLD stage IV than in stage II. SFC reduced the rate of $\mathrm{FEV}_{1}$ decline by $16 \mathrm{ml} /$ year versus placebo in GOLD stage II patients versus $11 \mathrm{ml} /$ year in stage IV patients which is comparable to the result reported in the overall population [13].

In our study, the incidence and severity of AEs was generally comparable across treatment arms, regardless of GOLD stage. Increased incidence of pneumonia has previously been reported with the use of ICS-containing therapy [2] and whilst this was observed, the probability of pneumonia with SFC in GOLD stage II patients was lower than that observed in the overall population. Further study is required however, to determine the exact mechanisms involved. There were too few on-treatment deaths from pneumonia to analyze these by GOLD stage.

It is important to note that, although GOLD stage II is defined by a post-bronchodilator $\mathrm{FEV}_{1}>50 \%$ but $<80 \%$ predicted [1], the upper limit for eligibility to the TORCH study was pre-bronchodilator $\mathrm{FEV}_{1}<60 \%$ predicted; therefore most patients would be expected to fall into the more severe end of stage II COPD, which was indeed found to be the case. The majority of patients who were diagnosed with GOLD stage II COPD had a baseline postbronchodilator $\mathrm{FEV}_{1}$ of $50 \%$ to $<60 \%$ (1360 patients [64\%], while 646 patients [30\%] had a $\mathrm{FEV}_{1} 60 \%$ to < $70 \%$ and only $122[6 \%]$ had a $\mathrm{FEV}_{1} 70 \%$ to $<80 \%$ ). This distribution appears to be similar to the $\mathrm{FEV}_{1} \%$ predicted distribution of stage II COPD patients from a 2005-2007 UK General Practice Research Database population-based cohort study [GSK Worldwide Epidemiology (WEUSKOP2207) Final study report, May 2009. Data on file] and the demographics of the TORCH GOLD stage II population is also similar to that of the UPLIFT clinical trial [10]. The majority of patients were also sufficiently symptomatic, as indicated by high baseline SGRQ total score, to have presented and been diagnosed with COPD, most likely as a result of exacerbations.

This analysis provides key information on pharmacotherapy in patients presenting with milder COPD and such data are lacking in the current literature and guidelines. Calverley and colleagues [5] performed a similar post-hoc analysis of the TRISTAN trial, but divided patients into $\mathrm{FEV}_{1}<50 \%$ predicted and $\geq 50 \%$ predicted and explored treatment differences by severity as a continuous variable.

Table 4: Pneumonia adverse events by post-bronchodilator FEV $\%$ predicted at baseline*

\begin{tabular}{|c|c|c|c|c|}
\hline & $\begin{array}{l}\text { Placebo } \\
(n=1544)\end{array}$ & $\begin{array}{c}\text { SAL } \\
(n=1542)\end{array}$ & $\begin{array}{c}\text { FP } \\
(n=1552)\end{array}$ & $\begin{array}{c}\text { SFC } \\
(n=1546)\end{array}$ \\
\hline \multicolumn{5}{|l|}{ FEV $_{1}<30 \%$ predicted } \\
\hline number of patients & 215 & 261 & 223 & 246 \\
\hline total treatment exposure (yrs) & 378 & 511 & 487 & 546 \\
\hline number of events & 28 & 44 & 55 & 89 \\
\hline rate $\ddagger$ & 74 & 86 & 113 & 163 \\
\hline \multicolumn{5}{|l|}{ FEV, $30 \%$ to $<\mathbf{5 0} \%$ predicted } \\
\hline number of patients & 786 & 750 & 785 & 735 \\
\hline total treatment exposure (yrs) & 1626 & 1686 & 1787 & 1752 \\
\hline number of events & 87 & 90 & $|7|$ & 156 \\
\hline rate $\ddagger$ & 54 & 53 & 96 & 89 \\
\hline \multicolumn{5}{|l|}{ FEV $_{\mathbf{I}} \geq \mathbf{5 0} \%$ predicted } \\
\hline number of patients & 543 & 531 & 544 & 565 \\
\hline total treatment exposure (yrs) & 1275 & 1334 & $|28|$ & 1402 \\
\hline number of events & 55 & 48 & 74 & 79 \\
\hline rate $\ddagger$ & 43 & 36 & 58 & 56 \\
\hline
\end{tabular}

*Safety population $(n=6184)$

$\ddagger$ Rate per thousand treatment years, calculated as (events $\times 1000 /$ total treatment exposure) 
Lung function was found to improve with active treatment, irrespective of $\mathrm{FEV}_{1}$, with greatest improvements reported for patients treated with SFC. In contrast to the findings reported here, only patients with more severe disease reported significantly reduced exacerbations; however health status and breathlessness both improved with active treatment irrespective of $\mathrm{FEV}_{1}$. The present findings provide further evidence that SFC can be used in patients with milder COPD.

Inevitably a post-hoc analysis of this type has limitations. The study was not designed to test for differences between GOLD stages or differences between treatment arms within GOLD stages. The numbers of patients in each stage were different and analyses of treatment subgroups within stages are underpowered. However, the size of the study ensured that the baseline characteristics of patients within each treatment arm was similar in each GOLD stage. TORCH recruited patients with a pre-bronchodilator $\mathrm{FEV}_{1}$ of $<60 \%$ predicted, but a substantial number of patients fell into GOLD stage II disease, being defined by spirometric severity based on the post-bronchodilator value. It is important to note that all had a clinical diagnosis of COPD and that the mean total SGRQ in stage II patients was 45 , indicating that they were a symptomatic group of patients. Finally, we adopted a conservative criterion with respect to study entry based on the former European Respiratory Society reversibility criterion of a change in $\mathrm{FEV}_{1}$ of less than $10 \%$ predicted. This is likely to have limited our ability to show changes in post-bronchodilator spirometry compared with studies where no reversibility limitation was present $[8,14]$. However, this is not likely to impact on our data for health status or exacerbations, which are unrelated to reversibility status [12].

\section{Conclusion}

Our data have clinical implications. Although patients in GOLD stage IV have worse outcomes such as health status impairment, higher exacerbation rates and mortality than did those in GOLD stage II, the latter group are not free from these important complications. Secondly, treatment is effective in GOLD stage II as well as in more severe stages of COPD. Finally, the results presented here suggest that patients with COPD may obtain important benefits from SFC combination pharmacotherapy, even at milder stages of disease.

\section{Competing interests}

CRJ has received consulting fees from Altana, AstraZeneca, Boehringer-Ingelheim and GlaxoSmithKline; speaking fees from Altana, AstraZeneca, Boehringer-Ingelheim, GlaxoSmithKline and Novartis; and grant support from GlaxoSmithKline. PWJ has received consulting fees from Almirall, AstraZeneca, GlaxoSmithKline, Novartis, Roche and Spiration; speaking fees from AstraZeneca and Glaxo-
SmithKline; and grant support from Boehringer-Ingelheim and GlaxoSmithKline. PMAC has received consulting fees from AstraZeneca, GlaxoSmithKline, Nycomed and Pfizer; speaking fees from GlaxoSmithKline and Nycomed; and grant support from Boehringer-Ingelheim and GlaxoSmithKline. BC has received consulting fees from Altana, AstraZeneca, Boehringer-Ingelheim and GlaxoSmithKline; speaking fees from Altana, AstraZeneca, Boehringer-Ingelheim and GlaxoSmithKline; and grant support from Boehringer-Ingelheim and GlaxoSmithKline. JAA is employed by and holds stock in GlaxoSmithKline. GTF has received consulting fees from BoehringerIngelheim, GlaxoSmithKline, Novartis and Schering Plough; speaking fees from Boehringer-Ingelheim, GlaxoSmithKline and Pfizer; and grant support from Altana, Boehringer-Ingelheim, Emphasys Medical Inc, Forrest, GlaxoSmithKline, Mannkind Corporation and Novartis. JCY is employed by and holds stock in GlaxoSmithKline. LRW is employed by and holds stock in GlaxoSmithKline. JV has received consulting fees from AstraZeneca, Boehringer-Ingelheim, GlaxoSmithKline, Hoffman-La Roche, Nycomed and Talecris; speaking fees from AstraZeneca, Boehringer-Ingelheim and GlaxoSmithKline; and grant support from GlaxoSmithKline; his wife has been an employee of GlaxoSmithKline and now works for AstraZeneca.

\section{Authors' contributions}

CRJ, PWJ, PMAC, BC, JAA, GTF, JCY and JV contributed to the initiation, design, and conduct of the study, the interpretation of data, and manuscript development; JAA and LRW designed and performed the statistical analyses. All authors have seen and approved the final submitted version of the manuscript.

\section{Acknowledgements}

We thank the patients and their families, the GlaxoSmithKline TORCH team and Karen Runcie (Gardiner-Caldwell Communications) for technical support in the preparation of the manuscript. This support was funded by GlaxoSmithKline. Manuscript administration charges were paid by GlaxoSmithKline.

\section{References}

I. Global Strategy for the Diagnosis, Management, and Prevention of Chronic Obstructive Pulmonary Disease [http:// www.goldcopd.com]

2. Calverley PM, Anderson JA, Celli B, Calverley PM, Anderson JA, Celli B, Ferguson GT, Jenkins C, Jones PW, Yates JC, Vestbo J, TORCH investigators: Salmeterol and fluticasone propionate and survival in chronic obstructive pulmonary disease. $N$ Engl J Med 2007, 356(8):775-789.

3. Wedzicha JA, Calverley PM, Seemungal TA, Hagan G, Ansari Z, Stockley RA, INSPIRE Investigators: The prevention of chronic obstructive pulmonary disease exacerbations by salmeterol/ fluticasone propionate or tiotropium bromide. Am J Respir Crit Care Med 2008, I 77(I): 19-26.

4. Zheng JP, Yang L, Wu YM, Chen P, Wen ZG, Huang WJ, Shi Y, Wang CZ, Huang SG, Sun TY, Wang GF, Xiong SD, Zhong NS: The efficacy and safety of combination salmeterol ( 50 microg)/fluticasone propionate (500 microg) inhalation twice daily via 
accuhaler in Chinese patients with COPD. Chest 2007, |32(6): | 756-| 763.

5. Calverley P, Pauwels RA, Jones PW, Anderson JA, Vestbo J: The severity of airways obstruction as a determinant of treatment response in COPD. Int J Chron Obstruct Pulmon Dis 2006, I(3):209-2I8

6. Calverley P, Pauwels R, Vestbo J, Jones P, Pride N, Gulsvik A, Anderson J, Maden C, TRial of Inhaled STeroids ANd long-acting beta2 agonists study group: Combined salmeterol and fluticasone propionate in the treatment of COPD: a randomised controlled trial. Lancet 2003, 36 I (9356):449-456.

7. Calverley PM, Boonsawat W, Cseke Z, Zhong N, Peterson S, Olsson $\mathrm{H}$ : Maintenance therapy with budesonide and formoterol in chronic obstructive pulmonary disease. Eur Respir J 2003, 22(6):912-919.

8. Hanania NA, Darken P, Horstman D, Reisner C, Lee B, Davis S, Shah $\mathrm{T}$ : The efficacy and safety of fluticasone propionate $(250$ microg)/salmeterol (50 microg) combined in the Diskus inhaler for the treatment of COPD. Chest 2003, 124(3):834-843.

9. Szafranski W, Cukier A, Ramirez A, Menga G, Sansores R, Nahabedian S, Peterson S, Olsson H: Efficacy and safety of budesonide/formoterol in the management of chronic obstructive pulmonary disease. Eur Respir J 2003, 21 (I):74-8I.

10. Decramer M, Celli B, Burkhart D, Kesten S, Mehra S, Liu D, Tashkin $D$ : The Effect of Tiotropium on COPD GOLD stage II during the four-year UPLIFT trial [abstract]. Am J Respir Crit Care Med 2009, 179:A2466.

II. Vestbo J, TORCH Study Group: The TORCH (TOwards a Revolution in COPD Health) survival study protocol. Eur Respir J 2004, 24(2):206-2I0

12. Calverley PM, Burge PS, Spencer S, Anderson JA, Jones PW: Bronchodilator reversibility testing in chronic obstructive pulmonary disease. Thorax 2003, 58(8):659-664.

13. Celli BR, Thomas NE, Anderson JA, Ferguson GT, Jenkins CR, Jones PW, Vestbo J, Knobil K, Yates JC, Calverley PM: Effect of pharmacotherapy on rate of decline of lung function in chronic obstructive pulmonary disease: results from the TORCH study. Am J Respir Crit Care Med 2008, I78(4):332-338.

14. Mahler DA, Wire P, Horstman D, Chang CN, Yates J, Fischer T, Shah $\mathrm{T}$ : Effectiveness of fluticasone propionate and salmetero combination delivered via the Diskus device in the treatment of chronic obstructive pulmonary disease. Am J Respir Crit Care Med 2002, 166(8): 1084-1091.

Publish with Bio Med Central and every scientist can read your work free of charge

"BioMed Central will be the most significant development for disseminating the results of biomedical research in our lifetime. "

Sir Paul Nurse, Cancer Research UK

Your research papers will be:

- available free of charge to the entire biomedical community

- peer reviewed and published immediately upon acceptance

- cited in PubMed and archived on PubMed Central

- yours - you keep the copyright
BioMedcentral 